\section{U.S. DEPARTMENT OF ENERGY}

\section{Office of}

ENERGY EFFICIENCY \& RENEWABLE ENERGY

\title{
Technology for Building Systems Integration and Optimization - Landscape Report
}


(This page intentionally left blank) 


\section{Preface}

The Department of Energy's (DOE) Building Technologies Office (BTO), a part of the Office of Energy Efficiency and Renewable Energy (EERE) engaged Navigant Consulting, Inc., (Navigant) to develop this report recommending.

The initiatives identified in this report are Navigant's research findings for BTO. Inclusion in this report does not imply any level of guaranteed funding or other type of support from BTO; initiatives must be evaluated in the context of all potential activities that BTO could undertake to achieve their goals.

Prepared for:

U.S. Department of Energy

Office of Energy Efficiency and Renewable Energy

Building Technologies Office - Commercial Building Integration

Prepared by:

Navigant Consulting, Inc.

77 South Bedford Street, Suite 400

Burlington, MA 01803

William Goetzler

Matt Guernsey

Youssef Bargach 


\section{Disclaimer}

This report was prepared by Navigant Consulting, Inc. (Navigant) for use of an agency of the United States Government. The work presented in this report represents Navigant's professional judgment based on the information available at the time this report was prepared. Navigant is not responsible for the reader's use of, or reliance upon, the report, nor any decisions based on the report. NAVIGANT MAKES NO

REPRESENTATIONS OR WARRANTIES, EXPRESSED OR IMPLIED. Readers of the report are advised that they assume all liabilities incurred by them, or third parties, as a result of their reliance on the report, or the data, information, findings and opinions contained in the report.

Neither the United States Government, nor any agency thereof, nor any of their employees, nor any of their contractors, subcontractors, or their employees, makes any warranty, express or implied, or assumes any legal liability or responsibility for the accuracy, completeness, or usefulness of any information, apparatus, product, or process disclosed, or represents that its use would not infringe privately owned rights. Reference herein to any specific commercial product, process, or service by trade name, trademark, manufacturer, or otherwise, does not necessarily constitute or imply its endorsement, recommendation, or favoring by the United States Government or any agency, contractor or subcontractor thereof. The views and opinions of authors expressed herein do not necessarily state or reflect those of the United States Government or any agency thereof. 


\section{Table of Contents}

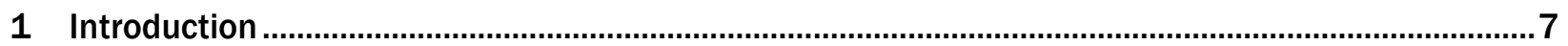

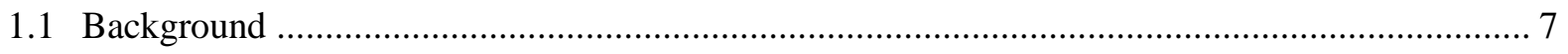

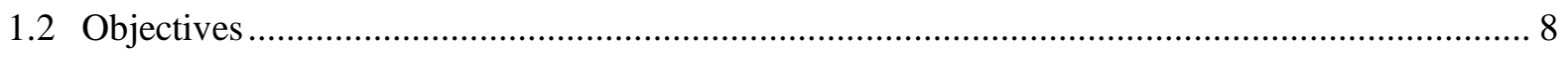

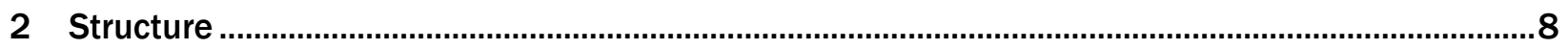

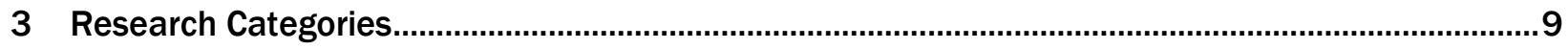

3.1 Integrated Multi-Technology Efficiency Packages .............................................................. 9

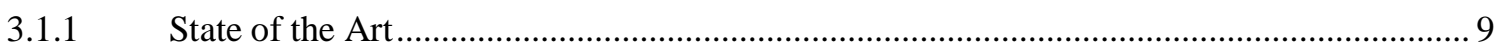

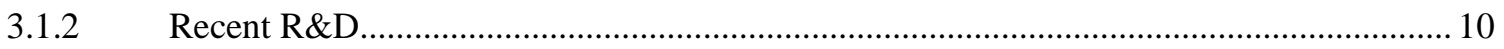

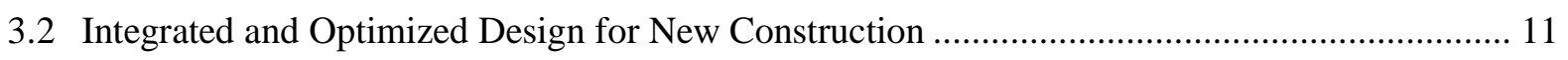

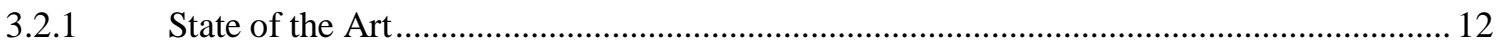

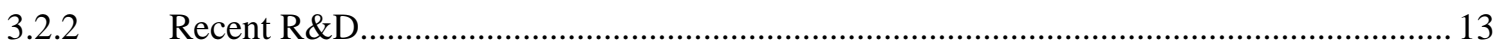

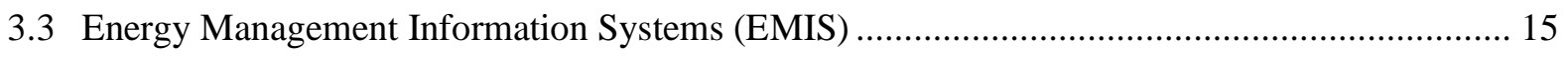

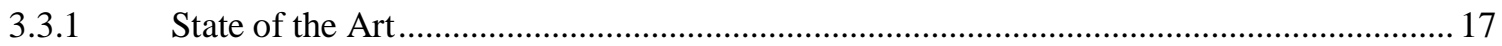

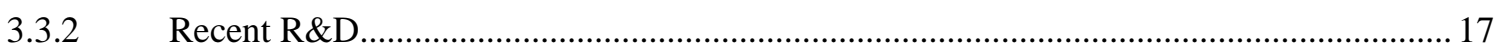

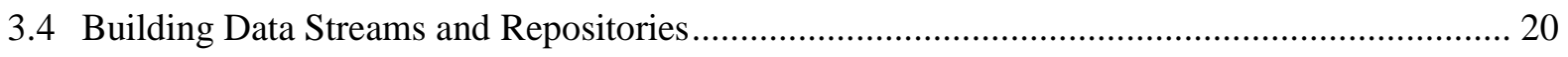

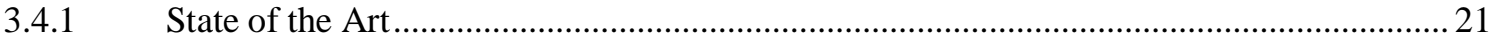

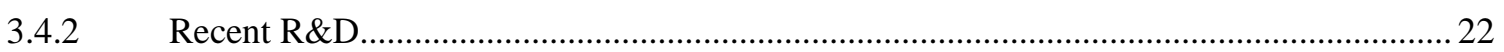

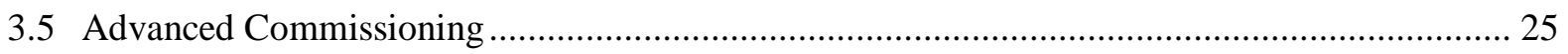

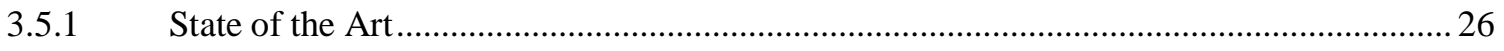

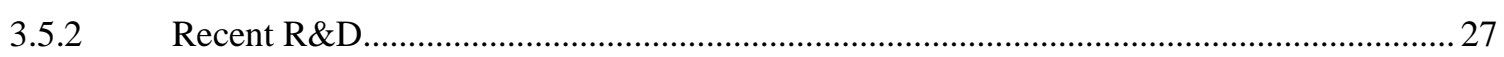

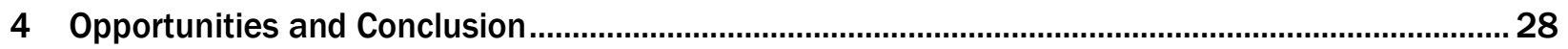




\section{List of Figures}

Figure 1. Systems Efficiency Building Blocks. ...............................................................................

Figure 2. Framework for Commercial Building Systems Integration and Optimization Technology....8

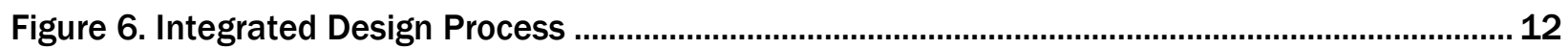

Figure 7. Schneider Energy Management Information System. ........................................................ 16

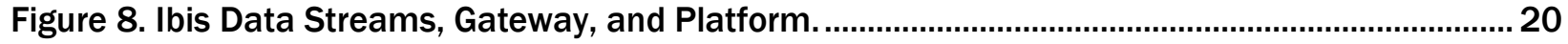

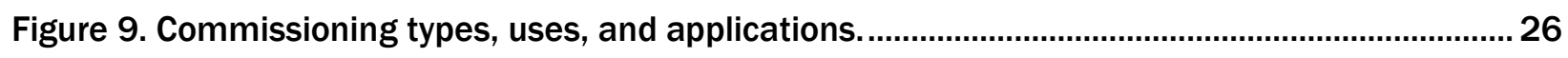

\section{List of Tables}

Table 1. Cutting Edge Solutions for Integrated Multi-Technology Efficiency Packages...................... 10

Table 2. Recent R\&D for Integrated Multi-Technology Efficiency Packages. ..................................... 11

Table 3. Cutting Edge Solutions for Integrated System Design Processes for ZNE........................... 13

Table 4. Recent R\&D for Integrated System Design Processes for ZNE ........................................... 14

Table 5. Sample Cutting Edge Solutions for Energy Management Information Systems. ................. 17

Table 6. Recent R\&D for Energy Management Information Systems................................................ 18

Table 7. Cutting Edge Solutions for Data Streams and Repositories................................................. 21

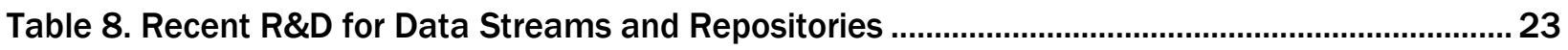

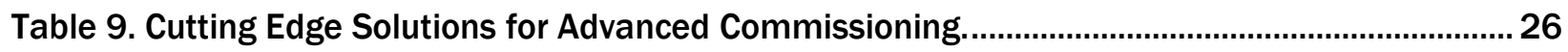

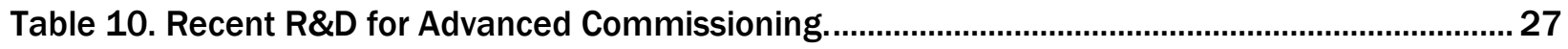




\section{Introduction}

\subsection{Background}

Within the Department of Energy (DOE), the Building Technologies Office's (BTO) Commercial Building Integration (CBI) program helps advance a range of innovative building integration and optimization technologies and solutions, paving the way for high-performing buildings that could use $50-70 \%$ less energy than typical buildings. CBI works with industry, small businesses, academia, utilities, the national labs and other entities to advance these innovations to minimize energy cost, reduce energy waste and improve commercial building performance. CBI works across multiple technical disciplines to understand industry needs so that U.S. businesses can save energy, time, and money.

CBI's work focuses on early stage technology innovation, with an emphasis on how components and systems work together and how whole buildings are integrated and optimized. This landscape study outlines the current body of knowledge, capabilities, and the broader array of solutions supporting integration and optimization in commercial buildings. CBI seeks to support solutions for both existing buildings and new construction, which often present very different challenges. Figure 1 shows possible systems efficiency building blocks and use cases as they relate to both new construction and existing buildings.

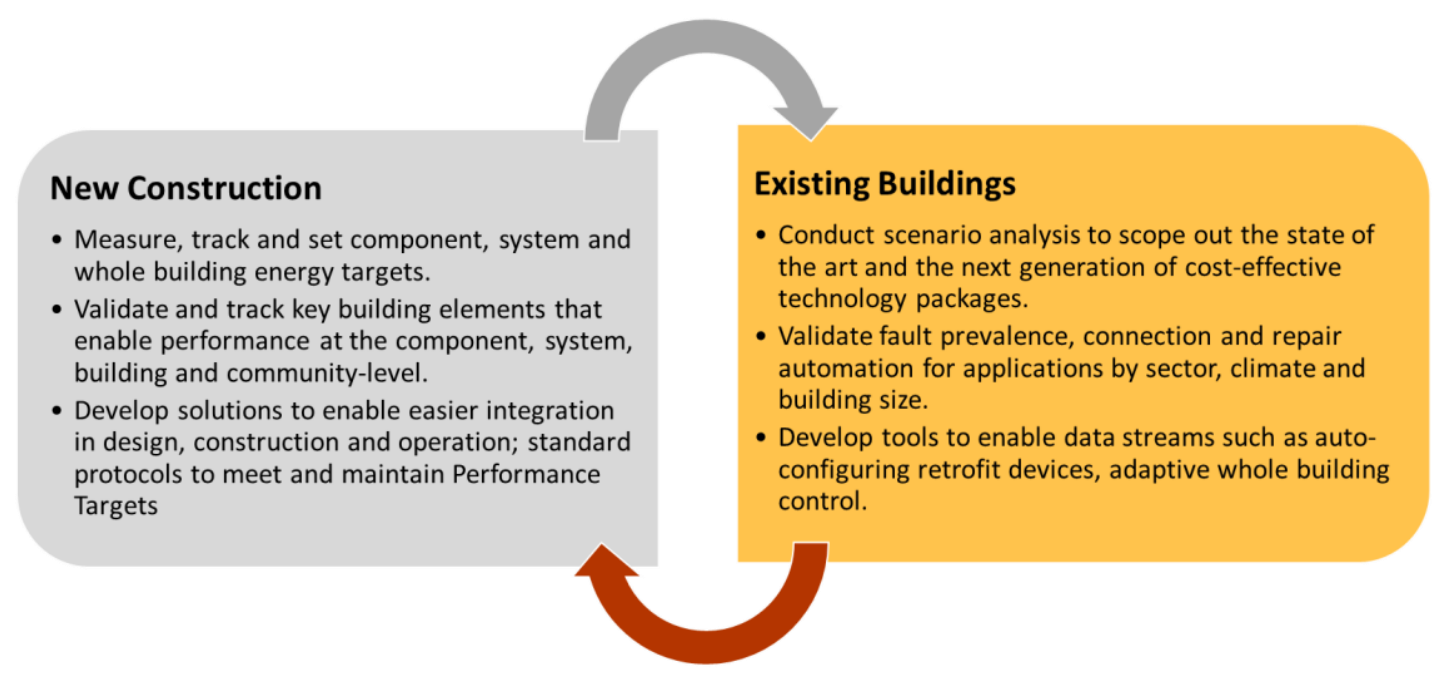

Ongoing private sector R\&D partnerships and federal coordination informs priorities at all stages.

Figure 1. Systems Efficiency Building Blocks.

CBI plays a unique role within BTO, focused on addressing the savings opportunities associated with the integration of components within systems and systems within buildings. CBI's investments seek to drive value between (and even beyond) the interactions of each energy consuming end use (or widget) within buildings. Incremental efficiency improvements and the development of novel, communicating and connected highefficiency technologies are critical to achieve BTO's ultimate energy goals. ${ }^{1}$ CBI's approach is to look

\footnotetext{
${ }^{1}$ BTO's goal is to reduce the average energy use per square foot of all U.S. buildings by $50 \%$ from 2010 levels.
} 
holistically at individual technologies and how they fit into a broader system to enable savings beyond what is achievable with basic widget-level initiatives.

\subsection{Objectives}

This landscaping exercise is the first step toward a deeper understanding of the new potential opportunities within the broader scope of existing commercial building integration and optimization solutions. By characterizing the state of the art and other current $R \& D$ activities, evaluating the energy savings impact across a broad set of building and systems and then identifying integration capabilities and needs, CBI can characterize and prioritize the integration research, development and field study necessary to achieve optimized and efficient, ultra-low energy buildings.

\section{Structure}

CBI seeks to understand what innovation can enable the achievement of maximum savings from emerging and pre-commercial solutions as they are integrated into (new and existing) building systems, ultimately achieving whole building energy savings and optimization. For this landscape study we have identified five key themes. These themes are laid out in a matrix that helps organize a broad range of existing, new and potential solutions into a logical framework for bucketing and reviewing existing internal and external activities, as shown in Figure 2. The figure represents these categories as they align at different levels of building integration: components, systems, buildings, and districts.

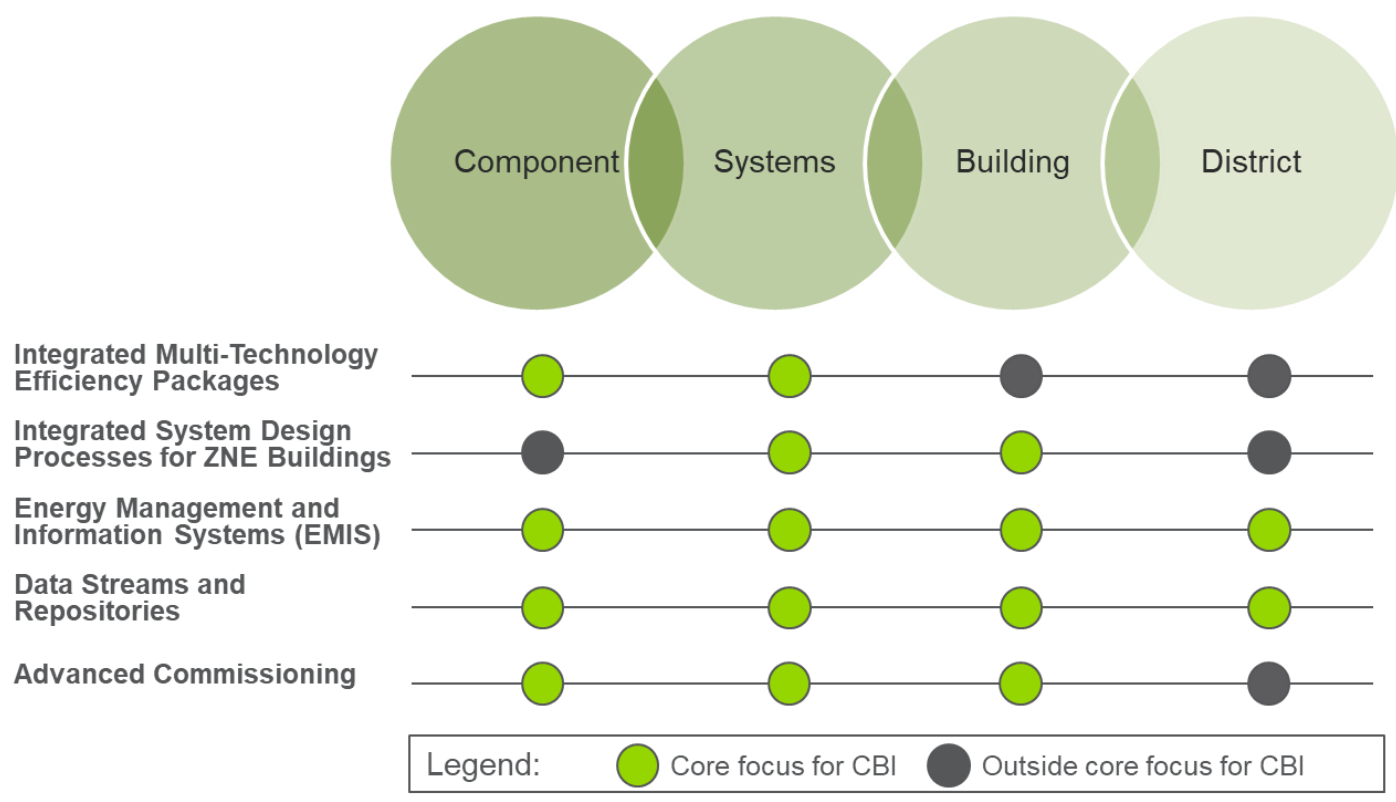

Figure 2. Framework for Commercial Building Systems Integration and Optimization Technology.2

This landscape study aims to provide insight into technology solutions that enable buildings and systems to better connect, communicate, store, evaluate, $\&$ automate across the different elements within the buildingenergy value chain. This work supports CBI's energy savings goals and lays the groundwork for enabling zero-net energy and ultra-low energy commercial buildings of the future.

\footnotetext{
${ }^{2}$ Source: http://energy.gov/eere/buildings/high-impact-technology-catalyst
} 


\section{Research Categories}

\subsection{Integrated Multi-Technology Efficiency Packages}

High-performance multi-technology efficiency packages optimize the integration of technologies that improve efficiency across two or more building systems. These prescriptive-like packages generally capture energy savings from opportunities that exist at the intersection of building systems (e.g. lighting system retrofits reduce the amount of heat contributed to the space, thus also reduce the HVAC's cooling load). The additional achievable systems-level savings (over the achievable savings of the

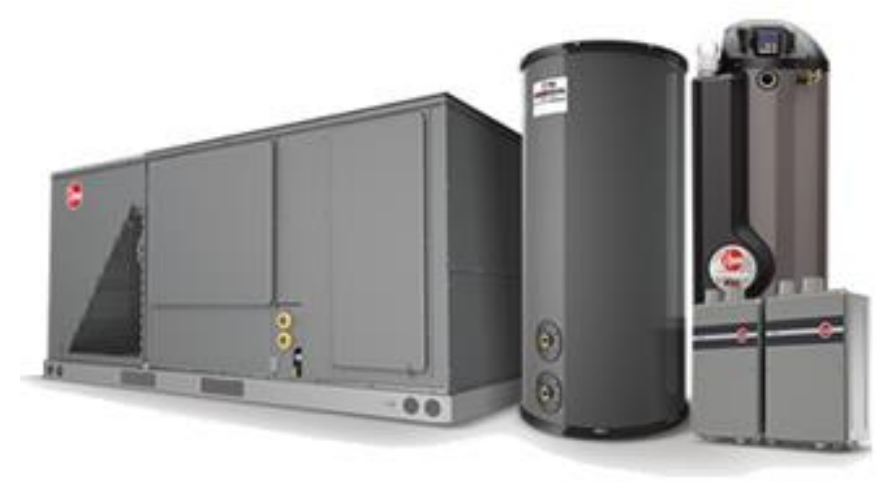
individual technologies that make up the package) can result from a variety of different opportunities, including but not limited to: energy load reduction, equipment downsizing, ease of integration with storage and generation solutions, the alignment if divergent but related building data streams or improved whole building communications and control.

This solution is broadly applicable in the commercial buildings market, however, it varies across building types. Traditionally, these packages require a high level of customization, have focused too specifically on a building sector, or system type, which has ultimately hindered the ability to create high impact multitechnology efficiency programs. For each building, we expect commercial stock analysis to show that the largest potential for energy savings exists at the interaction of the building systems with the highest energy loads, which may differ between building types. Analyses of those systems can identify the most impactful end uses for targeted integration and optimization activities and/or prescriptive-like package development. Given the increased cost of traditional custom approaches associated with this type of package, there is currently very limited application of these packages, but utilities and states are showing increased interest.

\subsubsection{State of the Art}

While numerous high-value emerging multi-technology efficiency packages are under development, including some with strong support from EERE, there is a limited number of available commercialized solutions. The customization requirements based on building type, location and size are one of the primary reasons for this low rate of commercialization and replication. Historically, the building equipment industry has been oriented around sales of individual, discrete systems or components, which represent most of the low-hanging fruit for energy savings in buildings. The industry is not yet accustomed to selling integrated packages. Individual service providers are generally equipped to provide one energy saving building technology but are not well suited to achieve the full spectrum of savings possible through integrated solutions. Where solutions are commercialized, including some specifically designed around utility energy efficiency programs, many are provided via partnerships between multiple service providers or manufacturers. Table 1 describes a sample of the cutting-edge solutions that are currently available from some of these organizations. 
Table 1. Cutting Edge Solutions for Integrated Multi-Technology Efficiency Packages.

\begin{tabular}{|c|c|}
\hline Organizations & Solution \\
\hline $\begin{array}{l}\text { View Electrochromics, Sage } \\
\text { Electrochromics, Enlightened, } \\
\text { Orama Lighting, et al. }\end{array}$ & Active Integrated Perimeter Building System \\
\hline \multicolumn{2}{|c|}{$\begin{array}{l}\text { A combination of lighting, controls, and loT devices for a dynamic building façade and lighting system } \\
\text { enabling savings for both lighting and HVAC loads at spaces adjacent to the building perimeter; the system } \\
\text { primarily manipulates fenestration solutions to achieve the perfect balance of natural lighting to reduce } \\
\text { building lighting needs, and thermal exchange through the window for reduced building HVAC loads } \\
2015 \text { DOE Peer Review Presentation; Available: } \\
\text { https://energy.gov/sites/prod/files/2015/05/f22/cbi57_Lee_041415.pdf }\end{array}$} \\
\hline $\begin{array}{l}\text { Univ. of Florida, Stonybrook } \\
\text { University, ORNL }\end{array}$ & A Combined Water Heater Dehumidifier and Cooler (WHDC) \\
\hline \multicolumn{2}{|c|}{$\begin{array}{l}\text { A low-cost, gas-fired heat pump water heater (HPWH) that leverages membrane-based absorption } \\
\text { technology to simultaneously meet cooling, dehumidification, and direct hot water (DHW) needs; such multi } \\
\text { technology solutions serve a primary function (in this case, enabling energy-savings for water heating } \\
\text { equipment), while simultaneously serving secondary functions, such as, reducing dehumidification and } \\
\text { cooling loads. } \\
2016 \text { DOE Peer Review Presentation; Available: } \\
\text { https://energy.gov/sites/prod/files/2016/04/f30/ACOM University\%20of\%20Florida Moghaddam- } \\
\text { 042516.pdf }\end{array}$} \\
\hline
\end{tabular}

\subsubsection{Recent R\&D}

Multi-technology efficiency packages can enable substantial energy savings, as demonstrated by some of the relevant $R \& D$ work described in Table 2 . Much of the pertinent $R \& D$ consists of assessments to evaluate the benefits of developing integrated, replicable multi-technology solutions versus further development of singlesystem or 'widget-based' technology advances. Moreover, much of the historical component or 'widget-based' R\&D has made significant progress with enabling technologies that have potential capabilities for integration within these multi-technology packages for additional savings and performance. The question remains: are they capable of rapid, cost-effective integration within a package? If not, what are the R\&D opportunities to enable that integration?

To support that assessment, ongoing CBI research also seeks to quantify the savings potential from interaction of key building systems compared to widget-based approaches. A primary challenge remains, however: evaluators lack uniform procedures to validate the performance of multi-technology solutions relative to that of individual components or widget-based solutions. ${ }^{3}$ An array of different stakeholders, particularly researchers and utilities, are conducting research to both quantify savings and establish the best practices for integrating multi-technology efficiency solutions into commercial buildings.

\footnotetext{
${ }^{3}$ M\&V 2.0 Demonstrations, led by LBNL and PNNL, combine automated analytics and data to estimate savings for building efficiency projects. Successful M\&V 2.0 implementation would result in streamlined savings estimations and potentially increased savings realizations for building energy saving measures.
} 
Table 2. Recent R\&D for Integrated Multi-Technology Efficiency Packages.

\begin{tabular}{|c|c|}
\hline Organization/Investigators & \\
\hline ACEEE & Beyond Widgets - Systems Incentive Programs for Utilities \\
\hline \multicolumn{2}{|c|}{$\begin{array}{l}\text { Evaluating utility systems-incentive-programs that go "beyond widgets" to provide utilities with proven and } \\
\text { standardized incentive programs that achieve savings at a system level without the necessity of costly } \\
\text { custom solutions. }\end{array}$} \\
\hline ComEd & Automated shading with daylighting and HVAC controls \\
\hline \multicolumn{2}{|c|}{$\begin{array}{l}\text { Field-testing of automated shading integrated with lighting and HVAC controls for reduced building energy } \\
\text { consumption; systems showed promising results from tests in schools and offices in medium/large } \\
\text { buildings; daylighting technologies alone showed between } 27 \% \text { and } 38 \% \text { savings }\end{array}$} \\
\hline California Publicly-Owned Utilities & $\begin{array}{l}\text { Lighting and plug load occupancy controls with task-ambient lighting } \\
\text { retrofit }\end{array}$ \\
\hline \multicolumn{2}{|c|}{$\begin{array}{l}\text { Field-testing of advanced controls for lighting and plug loads in commercial offices; occupancy sensors } \\
\text { control both lighting and plug loads; savings from these measures are approximately } 16 \%-21 \% \text { for the whole } \\
\text { building }\end{array}$} \\
\hline Xcel Energy & Daylight redirecting film with integrated lighting and HVAC controls \\
\hline \multicolumn{2}{|c|}{$\begin{array}{l}\text { Field testing of meso-optic film to direct incoming light towards the ceiling to improve ambient natural } \\
\text { lighting and minimize glare; lighting controls and occupancy sensors further modulate the building lighting } \\
\text { and HVAC systems for further savings }\end{array}$} \\
\hline Alliance to Save Energy & $\begin{array}{l}\text { Greater than the sum of its parts - the case for a systems approach to } \\
\text { energy efficiency }\end{array}$ \\
\hline \multicolumn{2}{|c|}{$\begin{array}{l}\text { Showing performance of energy packages relative to the sum of the parts, as it pertains to mechanical } \\
\text { systems, lighting, miscellaneous electric loads (MELs), multi-technology integration, and building-to-grid } \\
\text { integration. A wide array of benefits is available for each initiative type }\end{array}$} \\
\hline
\end{tabular}

\subsection{Integrated and Optimized Design for New Construction}

Integrated system design is a crosscutting approach to building design and engineering that focuses on bringing designers, engineers and builders together using holistic design methods (rather than the independent, sometimes disaggregated design of individual building systems) to achieve new, innovative, and optimized buildings and building systems. While integrated system design is applicable to low-energy buildings in general, the focus here is specifically on new construction and how new buildings can be designed, constructed and operated to:

- Measure, track and set component, system and whole building energy targets,

- Validate and track key building elements that enable more autonomous operation and energy performance, and

- Model rapid, cost-effective design, construction and operation that meets and maintains energy performance targets.

The integrated system design process focuses on the intentional consideration of trade-offs and interactions between building systems, in tandem, to optimize operations and energy savings. Integrated system design seeks to capitalize on the many opportunities for energy savings that exist at the intersection of building systems. Figure 3 provides a flow chart of an example process. 


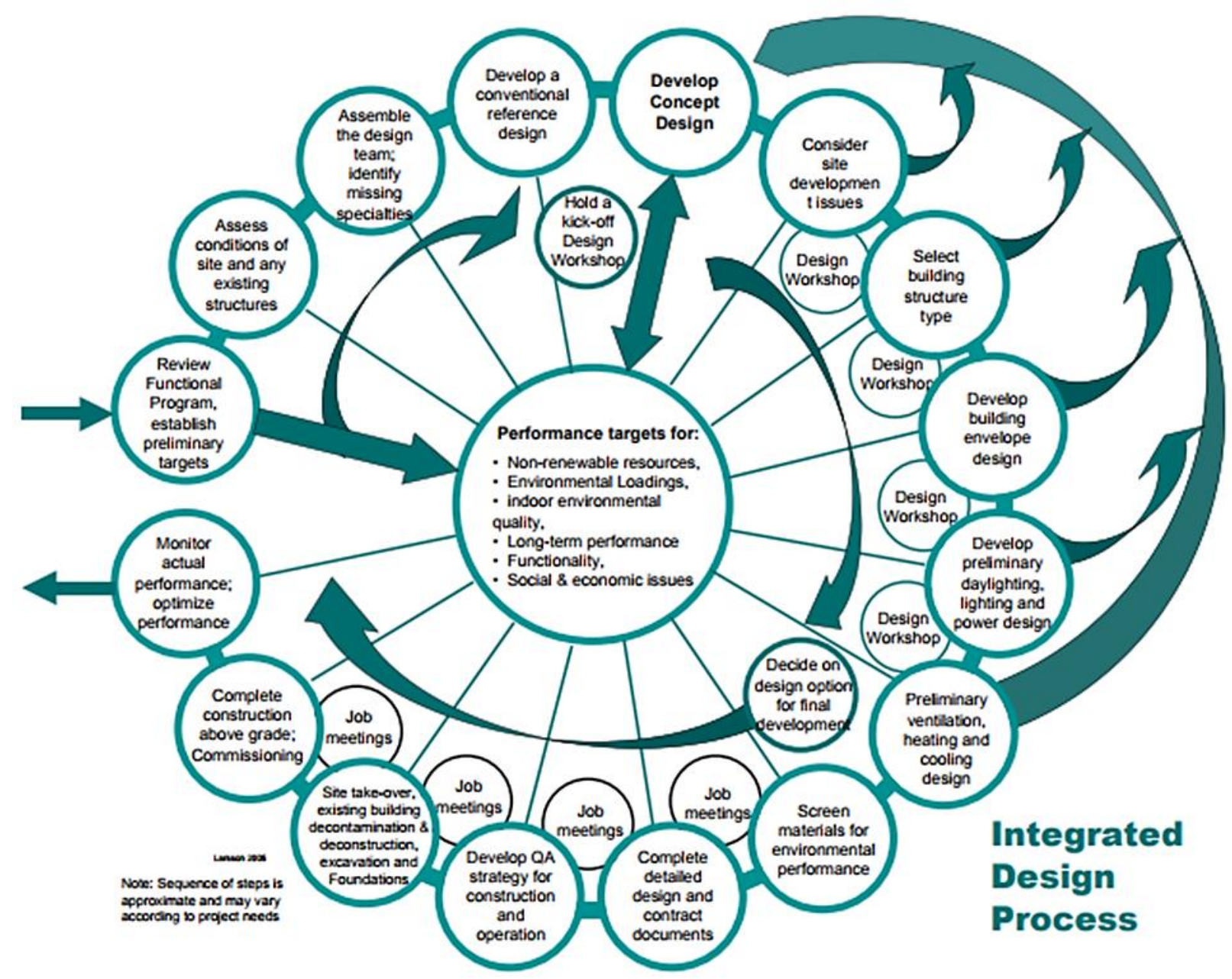

Figure 3. Integrated Design Process 4

At the core of this process is the method that governs how architecture and engineering firms operate, both internally and with their clients. The approach stresses constant communication between all stakeholders in the design and construction process as it is critical to ensuring that building designers incorporate new connectivity and automation opportunities to enable big data analytics, model-predictive control, automated performance validation, grid interactive operation, and other such capabilities. To successfully achieve integrated and optimized buildings, stakeholders must reconsider their energy modeling workflows, overall use of data and, processes for handing off the building post-construction.

\subsubsection{State of the Art}

Design approaches for new construction and major renovations heavily influence whole building efficiency and can have a substantial impact if approached collaboratively from the outset of building design. Many existing and emerging technologies and processes enable integrated system design. These existing integrated

\footnotetext{
${ }^{4}$ Source: http://www.iisbe.org/system/files/private/IDP\%20development\%20-\%20Larsson.pdf
} 
design solutions, however, are far from standard practice and will require significant acceptance from crossfunctional design and operations teams before they can yield notable benefits. The growth in recent years of design-build contracts (one in which the project is designed and constructed by a single team) is an enabler that may help accelerate the use of integrated design solutions but, in many cases, still lacks ownership and accountability for ultimate building performance once the building is constructed. Table 3 identifies some of the best-in-class tools and guides that enable integrated system design.

Table 3. Cutting Edge Solutions for Integrated System Design Processes for ZNE.

\begin{tabular}{|c|c|}
\hline Organization & olution \\
\hline ASHRAE & Guides on integrated design for sustainable buildings \\
\hline \multicolumn{2}{|c|}{$\begin{array}{l}\text { Building guides with steps detailing the implementation of integrated design as it pertains to load reduction, } \\
\text { system efficiency optimization, regenerative systems, and renewable sources } \\
\text { Design guide available: } \underline{\text { https://www.ashrae.org/File\%20Library/docLib/Public/2006458559 686.pdf }}\end{array}$} \\
\hline Autodesk & Building Information Modeling (BIM) \\
\hline \multicolumn{2}{|c|}{$\begin{array}{l}\text { 3D building modeling and workflow management tools to create a shared knowledge resource supporting } \\
\text { the design process for architecture, engineering, and construction (AEC) of buildings and infrastructure } \\
\text { Solution provider information available: } \underline{\text { https://www.autodesk.com/solutions/bim }}\end{array}$} \\
\hline EnergyPlus & Building Energy Modeling (BEM) \\
\hline \multicolumn{2}{|c|}{$\begin{array}{l}\text { Energy simulation software accounting for whole building energy parameters as an input driving more } \\
\text { focused integrated system design; Building Energy Modeling acts as a bridge between design/construction } \\
\text { and operations as it can be leveraged for model predictive control and operation in the building } \\
\text { EnergyPlus information available: https://apps1.eere.energy.gov/buildings/energyplus/ }\end{array}$} \\
\hline University of Pennsylvania & $\begin{array}{l}\text { MLE+: A Tool for Integrated Design and Deployment of Energy Efficient } \\
\text { Building Controls }\end{array}$ \\
\hline \multicolumn{2}{|c|}{$\begin{array}{l}\text { Tool for building automation design, co-simulation, and analysis. The solution combines the energy } \\
\text { modeling capabilities of EnergyPlus with Matlab to enable improved controller design, system optimization, } \\
\text { and simulation analyses. } \\
\text { Technology research available: } \\
\text { https://repository.upenn.edu/cgi/viewcontent.cgi?article=1069\&context=mlab_papers }\end{array}$} \\
\hline $\begin{array}{l}\text { Commission for Environmental } \\
\text { Cooperation }\end{array}$ & Guide to Integrated Design and Delivery \\
\hline \multicolumn{2}{|c|}{$\begin{array}{l}\text { Guide on best practices for integrated building design spanning the full project lifecycle from goal setting to } \\
\text { business model/contract structure to road mapping and execution. Key contract models discussed are: } \\
\text { - Multi-party contracts - owner, architect, and general contractors are bound in the risk/reward } \\
\text { structure with sub-agreements for subcontractors; they have final decision-making power } \\
\text { Poly-party contracts - extending the risk/reward structure to include all team members; everyone } \\
\text { receives a vote in the design process including owners, designers, HVAC contractors, steel erectors, } \\
\text { framers, equipment vendors, etc. } \\
\text { Full guide available at: http://www3.cec.org/islandora/en/item/11661-improving-green-building- } \\
\text { construction-in-north-america-guide-integrated-design-en.pdf }\end{array}$} \\
\hline
\end{tabular}

\subsubsection{Recent R\&D}

A majority of the research in this space focuses on the different methods capable of promoting and incorporating system integration techniques into current building-design processes. Many central components of these methods will require a cultural shift by design and engineering firms to put a heavier emphasis on the use of newly available real building data to inform design assumptions, set energy savings targets, and continue accountability past design and into the operation of the completed building. Current processes fail to prioritize energy performance as a design consideration and use outdated equipment and systems performance data to support energy analysis, if it is done at all. These processes will be insufficient to achieve optimized 
whole building energy performance and will be unable to realize the full benefits of automated, connected buildings. New solutions face substantial inertia in industry as current processes are well-established and respected. Table 4 highlights some of the ongoing and recent R\&D.

Table 4. Recent R\&D for Integrated System Design Processes for ZNE

\begin{tabular}{|c|c|}
\hline Organization/Investigators & QD Activity \\
\hline LBNL & \\
\hline \multicolumn{2}{|c|}{$\begin{array}{l}\text { Identifying the additional energy savings that are made possible through the use of integrated system } \\
\text { retrofits in buildings; solutions manipulate the interactive effects between building systems to enable } \\
\text { savings through smaller equipment sizing or lower energy technologies. The Integrated System is the only } \\
\text { method shown to achieve savings of }>50 \% \text { for building retrofits } \\
\text { Case Study available: http://www.sciencedirect.com/science/article/pii/S0378778817318832 }\end{array}$} \\
\hline ACEEE & $\begin{array}{l}\text { You Can't Beat the System: The Case for a Systems Approach to } \\
\text { Commercial Building Efficiency }\end{array}$ \\
\hline \multicolumn{2}{|c|}{$\begin{array}{l}\text { Defining processes to enable systems approach to building energy efficiency; quantifying any likely non- } \\
\text { energy saving benefits (e.g. reliability, comfort, water savings, etc.) which are estimated to account for } \\
\text { between } 25-50 \% \text { of the total benefit of a systems approach }\end{array}$} \\
\hline Green Building Roundtable & Roadmap for the Integrated Design Process \\
\hline \multicolumn{2}{|c|}{$\begin{array}{l}\text { Identifying the best practices for system integration and proving the validity of the findings through a series } \\
\text { of case studies. In one such case, the integrated design process resulted in a } 50 \% \text { increase in building } \\
\text { performance relative to the Canadian Model National Energy Code. } \\
\text { Roadmap guide and reference manual available: http://www.greenspacencr.org/events/IDProadmap.pdf }\end{array}$} \\
\hline Alliance to Save Energy & \\
\hline \multicolumn{2}{|c|}{$\begin{array}{l}\text { Identifying key opportunities for building-systems based energy efficiency through an evaluation of key } \\
\text { building systems and their interactions; providing specific recommendations for actions that can achieve } \\
\text { greater adoption, while identifying critical stakeholders and their roles in implementing those } \\
\text { recommendations } \\
\text { Paper available: http://www.ase.org/sites/ase.org/files/ase-sei_going_beyond_zero-digital-vf050317.pdf }\end{array}$} \\
\hline ASHRAE & Integrated Design for Sustainable Buildings \\
\hline \multicolumn{2}{|c|}{$\begin{array}{l}\text { Quantifying potential benefits of early-design collaboration while highlighting the diminishing returns } \\
\text { associated with delaying design collaboration; establishing a clear process, with associated roles for } \\
\text { players in the integrated design process. } \\
\text { Resources available: https://www.ashrae.org/membership--conferences/student-zone/design- } \\
\text { competition/2017-integrated-sustainable-building-design }\end{array}$} \\
\hline US DOE & $\begin{array}{l}\text { Integrated Design - Delivery and Operations of Net-Zero Energy } \\
\text { Buildings }\end{array}$ \\
\hline \multicolumn{2}{|c|}{$\begin{array}{l}\text { Identifying the processes and information flows necessary across different phases of a building's lifecycle, } \\
\text { as well as an estimate of the associated engineering costs, in order to achieve a ZNE building. } \\
\text { Solar Decathlon presentation available: } \\
\text { https://www.solardecathlon.gov/past/pdfs/09 workshops/09 integrated design.pdf }\end{array}$} \\
\hline
\end{tabular}


Documenting the status and lessons learned from case studies and initiatives funded by GSA's Office of Federal High-Performance Green Buildings; the document provides specific recommendations that can lead to high efficiency buildings, including recommendations at the Integrated Project Delivery/Integrated Design phases.

Research report available: https://www.wbdg.org/files/pdfs/integration_at_its_finest.pdf

\begin{tabular}{l|l}
$\begin{array}{l}\text { California State University, U.S. Army } \\
\text { Corps of Engineers, etc. }\end{array}$ & $\begin{array}{l}\text { Automation in Construction - Analysis of an energy efficient } \\
\text { building design through data mining approach }\end{array}$
\end{tabular}

Identifying data mining technologies and processes that can facilitate the handling of building data necessary to design an energy efficient building. The energy simulations required to implement data-driven integrated whole-building processes generate large volumes of data that need to be mined for effective use in the building design process.

Research report available:

http://www.sciencedirect.com/science/article/pii/S0926580510001044?via\%3Dihub

LBNL Co-simulation of building energy and control systems with the Building Controls Virtual Test Bed

Presenting the Building Controls Virtual Test Bed (BCVTB), a modular and extensible software platform allowing for the simultaneous processing of multiple building-system simulations. The co-simulations enable computation of coupled problems such as building heat transfer and HVAC system dynamics and control algorithms.

Research available: https://www.researchgate.net/profile/Michael_Wetter/publication/233258018_Cosimulation_of_building_energy_and_control_systems_with_the_Building_Controls_Virtual_Test_Bed/links/5 56dfc2508aeab7772269edd/Co-simulation-of-building-energy-and-control-systems-with-the-BuildingControls-Virtual-Test-Bed.pdf

\begin{tabular}{l|l} 
Energy Design Resources & Design Brief - Performance-based compensation
\end{tabular}

Exploration of the potential benefits of performance-based compensation contracts in incentivizing members of the integrated design process to design buildings such they meet performance goals post construction. The standard structure involves establishing a baseline energy specification as well as a penalty/reward structure proportional to deviations from that target.

Design brief available:

https://energydesignresources.com/media/1774/EDR DesignBriefs perfcompensation.pdf

University of Singapore

Using a data-driven approach to support the design of energyefficient buildings

Presenting a potential data-driven approach that can facilitate the accuracy and performance of design iterations required in the integrated design process. Given the volume of data generated during the integrated design process, there is a need for improved accuracy and decreased data processing times. Research report available: http://www.itcon.org/papers/2015_6.content.00001.pdf

\subsection{Energy Management Information Systems (EMIS)}

Energy Management Information Systems comprise a set of software solutions (often hardware-enabled) intended to access various building data, aggregate the data, and analyze the resulting trends for optimization and efficiency opportunities. EMIS coupled with expansive, dynamic sets of real building data (see section 3.4, below) can provide comprehensive optimization solutions for commercial buildings. EMIS generally encompasses the front-end system that users interact with as well some middleware to help manage data inputs and other layered-on analytical tools. 


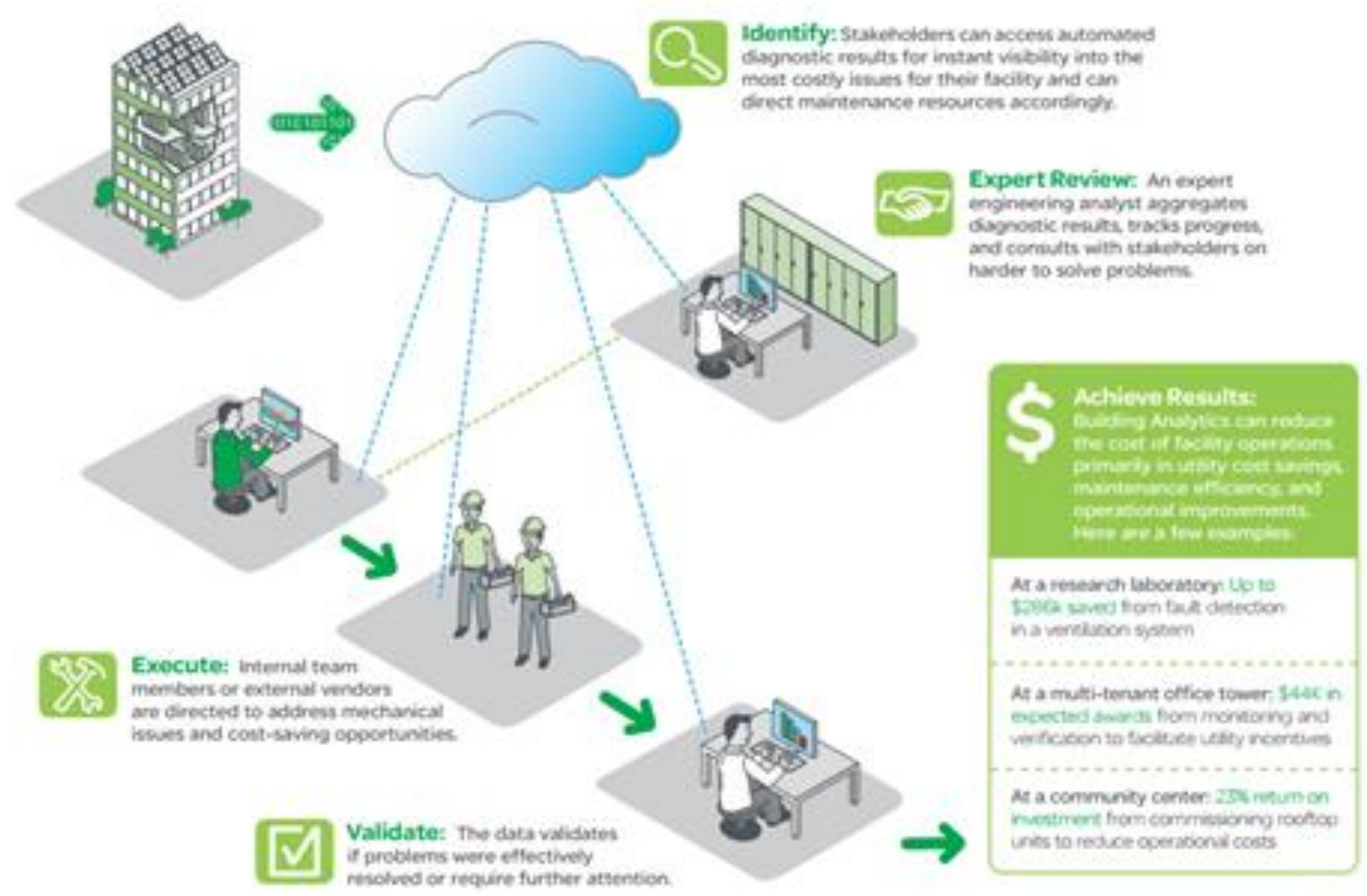

Figure 4. Schneider Energy Management Information System. ${ }^{5}$

Building owners can leverage real-time building-data trend analysis for improved energy benchmarking, operational optimization (e.g. syncing occupancy and comfort with operational protocols and control), identification of energy saving opportunities (e.g. replacement or maintenance of inefficient equipment), and building performance evaluation. EMIS Tools ${ }^{6}$ comprise the following categories:

- Benchmarking and utility bill analysis

- $\quad$ Energy Information System (EIS) and Advanced EIS

- Building Automation System (BAS)

- Fault Detection Diagnostics (FDD)

- Automated System Optimization (ASO)

Energy analytics and energy information management is essential to maintaining operational excellence, identifying and verifying savings, participating in demand response programs, balancing storage, generation and loads, and creating connected, interactive building components and systems. Increased adoption of these solutions can heavily impact the way energy managers and businesses manage their whole-building energy

\footnotetext{
${ }^{5}$ Source: https://www.schneider-electric.us/documents/buildings/Building-Analytics-Brochure.pdf

${ }^{6}$ More at: https://betterbuildingsinitiative.energy.gov/sites/default/files/attachments/emis-crash-course.pdf
} 
consumption, particularly those of large commercial buildings, campuses (co-located), and broad portfolios of buildings (not co-located). Because individual building sectors have distinct needs when it comes to managing energy and building systems, most EMISs are tailored to one or more building types to provide the most value for a focused market.

\subsubsection{State of the Art}

Many solutions exist or are rapidly emerging in this area, many of which build on core analytical trends by aiming to become an integral part of daily building operations, bringing together formerly disparate solutions such as fault detection diagnostics (FDD), forecasting, modeling, measurement and verification (M\&V), occupant input, and cloud computing capabilities.

Table 5. Sample Cutting Edge Solutions for Energy Management Information Systems.

\begin{tabular}{|c|c|}
\hline Organizations & \\
\hline BuildingIQ & 5i Intelligent Energy Platform \\
\hline \multicolumn{2}{|c|}{$\begin{array}{l}\text { Energy Management Information System for data capture analysis, advanced building energy modeling, } \\
\text { M\&V, and predictive control, among others } \\
\text { Solution provider website available: } \underline{\text { https://buildingiq.com/products/5i-intelligent-energy-platform/ }}\end{array}$} \\
\hline IBM & TRIRIGA Facilities Manager \\
\hline \multicolumn{2}{|c|}{$\begin{array}{l}\text { Integrated solutions based in a real estate management software platform; the software assists in the } \\
\text { identification of underutilized building resources to enable higher utilization, cost reductions, and energy } \\
\text { savings. } \\
\text { Solution provider website available: http://www-03.ibm.com/software/products/en/ibmtriffacimana }\end{array}$} \\
\hline EnerNOC & Software to Tackle Every Aspect of Energy Management \\
\hline \multicolumn{2}{|c|}{$\begin{array}{l}\text { Software platform providing several building data management solutions, including but not limited to utility } \\
\text { bill management, sustainability \& reporting, and facility analysis \& optimization } \\
\text { Solution provider website available: } \underline{\text { https://www.enernoc.com/products/capabilities- }} \\
\text { businesses/capabilities }\end{array}$} \\
\hline Energent & Energy Management Information System \\
\hline \multicolumn{2}{|c|}{$\begin{array}{l}\text { Cloud-based EMIS software solution providing building energy management and building optimizations } \\
\text { driven by multiple data acquisition methods } \\
\text { Solution provider website available: } h \text { ttp://www.energent.com/emis/ }\end{array}$} \\
\hline Siemens & Building Automation and Control Systems \\
\hline \multicolumn{2}{|c|}{$\begin{array}{l}\text { Building Automation Systems upon which many building systems including HVAC, lighting, security, etc. can } \\
\text { be integrated, controlled, and monitored } \\
\text { Solution provider website available: } \\
\text { https://w5.siemens.com/greece/internet/en/pss/IC/BT/tra/Documents/Download\%20(2).pdf }\end{array}$} \\
\hline Honeywell & Building Automation System with Controllers \\
\hline $\begin{array}{l}\text { Open BAS plat } \\
\text { controllers can }\end{array}$ & $\begin{array}{l}\text { interfacing with building managers and occupants to which Honeywell } \\
\text { ify data and convert data to action via output devices (i.e. actuators) } \\
\text { https://buildingcontrols.honeywell.com/Building-Automation-Systems }\end{array}$ \\
\hline
\end{tabular}

\subsubsection{Recent R\&D}

Many R\&D activities focus on determining or verifying the functionality, application, and impact of EMIS in existing buildings. Savings projections from EMIS are often difficult to characterize due to variations between buildings and management staff and the need for human intervention to execute recommended improvements that are found using the EMIS. That is to say, most of these systems are not currently supervisory or integrated in order to automate building components or systems. With extensive competition among EMIS providers, 
there is limited consistency between products and claims by one EMIS are not indicative of claims from any other EMIS.

A significant challenge associated with the variations in EMIS technologies surrounds their underlying, enabling, sensing and connectivity requirements. Different EMIS solutions leverage data from different sensors using different formats and communicating over different protocols, making unification on a comprehensive data platform difficult but necessary.

Many of the advancements in EMIS solutions seek to find cheaper means for data collection, such as low-cost multi-sensor arrays. The reason for this focus is that the sensor technologies themselves are sufficient and capable of providing the data necessary to enable EMIS solutions, however, for large-scale deployment, cost reductions are vital. With a robust sensor network, there is also an increased need for data management. Data storage is becoming significantly cheaper and more accessible, allowing for the feasible creation of large building datasets. As a result, many data repositories exist (discussed further in Section 3.4). EMIS solutions, however, need to evolve to make better use of that data, particularly through machine learning and pattern recognition.

$\mathrm{R} \& \mathrm{D}$ related to energy analytics and building management is different from that of the other research categories in this report. The solutions in this space offer many similar functions, components, and capabilities but are combined and delivered in a wide variety of ways. Each solution is generally tailored towards a different sector, market or building system and continues to evolve as the providers (often start-up software firms) continually pivot, refine, and optimize to meet market needs and become commercially successful. The $\mathrm{R} \& \mathrm{D}$ focuses on identifying the right set of capabilities to achieve the highest energy savings and overall value to the customer and then quantifying that savings potential.

Table 6. Recent R\&D for Energy Management Information Systems.

\begin{tabular}{|l|l|}
\hline Organization/Investigators & $\begin{array}{l}\text { R\&D Activity } \\
\text { Building Analytics - Improve the efficiency, occupant comfort, } \\
\text { and financial well-being of your building. }\end{array}$ \\
\hline $\begin{array}{l}\text { Quantifying the energy consumption and cost of Energy Analytics and Management, through an analysis of } \\
\text { data from systems deployed at customer sites; identifying operational and energy performance } \\
\text { opportunities, particularly those related to AFDD, monitoring, and reporting } \\
\text { Solution provider website available: https://www.schneider-electric.us/documents/buildings/Building- } \\
\text { Analytics-Brochure.pdf }\end{array}$ \\
\hline $\begin{array}{l}\text { Institute for Building Efficiency, Johnson } \\
\text { Controls }\end{array}$ & Building Energy Management: Using Data as a Tool \\
\hline $\begin{array}{l}\text { Quantifying the state of energy analytics and management in industry, and characterizing the capabilities of } \\
\text { such solutions, including but not limited to: trend analysis, benchmarking, FDD, energy forecasting, M\&V, } \\
\text { and big data analytics } \\
\text { Solution provider white paper available: } \\
\text { http://www.buildingefficiencyinitiative.org/sites/default/files/legacy/InstituteBE/media/Library/Resources/ } \\
\text { Existing-Building-Retrofits/Using-Building-Data-as-a-Tool.pdf }\end{array}$ \\
\hline $\begin{array}{l}\text { Loughborough University } \\
\text { Challenges and potential of BIM for building energy } \\
\text { performance visualization and management }\end{array}$ \\
\hline $\begin{array}{l}\text { Assessing the impact of building information modeling (BIM) as a tool to improve building operational } \\
\text { performance; the investigation incorporates inputs from building designers and operators to develop the } \\
\text { best methodologies for data collection and visualization. } \\
\text { Research paper available: http://www.sciencedirect.com/science/article/pii/SO378778817308770 }\end{array}$ \\
\hline
\end{tabular}


Organization/Investigators

University College London
R\&D Activity

Improving energy efficiency via smart building energy

management systems: A comparison with policy measures

Quantifying the energy savings potential of Smart Building Energy Management Systems (BEMS) utilizing dynamic set points over those with static set points, which policymakers abroad have supported, particularly in the context of promoting smart grids

Research paper available: http://www.sciencedirect.com/science/article/pii/S0378778814010469

\begin{tabular}{l|l} 
ACEEE & Wireless Sensors Networks for Advanced Energy Management
\end{tabular}

Evaluation of EMIS enabling sensing technologies for the industrial community, including multi-sensor array platforms, Quality-of-Service for reliable data transmission from distributed sensors, and self-configuring wireless sensor networks, Research also includes details on microsensor arrays, ultra-low power electronics, and control transceivers.

Research paper available:

https://aceee.org/files/proceedings/2005/data/papers/SS05 Panel01 Paper10.pdf

\section{SINTEF ICT}

Case study for the integration of a wireless sensor network with internet service communications into a knowledge and information services platform for energy management. The proposed approach enables the collection of energy information from devices across building systems operating with different communication protocols.

Case study available: http://www.itcon.org/papers/2012 3.content.00598.pdf

\begin{tabular}{l|l} 
NIST & $\begin{array}{l}\text { Measurement Science Roadmap for Net-Zero Energy } \\
\text { Buildings }\end{array}$ \\
\hline
\end{tabular}

Evaluation of available measurement technologies and identification of key challenges and priorities surrounding future capabilities of these technologies. Specific commentary surrounding enabling technologies for intelligent buildings including control systems, sensors, and whole building global optimization and systems integration.

Workshop summary report available: http://ws680.nist.gov/publication/get_pdf.cfm?pub_id=905024 NIST Advanced Sensing Systems for Building Energy Monitoring

Project to advance the capabilities of existing sensing technologies through miniaturization of existing components and incorporation of microprosessing capabilities within sensors. The project is specifically geared at optimizing sensor networks for integration into monitoring systems to quantify thermal transmission through envelopes.

Project description available: https://www.nist.gov/programs-projects/advanced-sensing-systems-buildingenergy-monitoring

Electronics and Telecommunications

Research Institute

Automatic sensor arrangement system for building energy and environmental management

Proposal of two automatic sensor arrangement systems to determine the best installation location for sensors automatically as opposed to manually. The primary sensors considered include temperature, humidity, illuminance, motion, and $\mathrm{CO}_{2}$ sensors.

Research paper available: http://www.sciencedirect.com/science/article/pii/S187661021104344X

King Saud University An Intelligent Energy Management System for Educational Buildings

Research report proposing refined strategies needed to achieve a service oriented architecture (SOA) for a uniform system to handle campus energy data. The research recommends strategies for improved system design and the management of large volumes of component data,

Research paper available: http://journals.sagepub.com/doi/full/10.1155/2013/209803 


\subsection{Building Data Streams and Repositories}

Building data streams and repositories are an effective way to make extensive building data sets valuable for contribution, access and use by and between end-users who may be researchers, commissioning providers, energy modelers, designers, operators or utilities. Data streams and repositories can enable better energy management and automation and build on advances in building-system interoperability. Solutions in this category include a combination of hardware and software offerings and serve as the back-end solutions to enable effective use of front-end EMIS. These two sets of solutions, data streams and repositories and EMIS, provide comprehensive solutions for gathering, managing, and analyzing data to improve operational performance, energy consumption, identify investment opportunities, participate in dynamic tariffs and demand response programs, balance storage, generation and loads, and create grid-responsive building components and systems for possible aggregation with other buildings. Figure 5 provides an overview of the key elements in one service provider's overarching architecture.
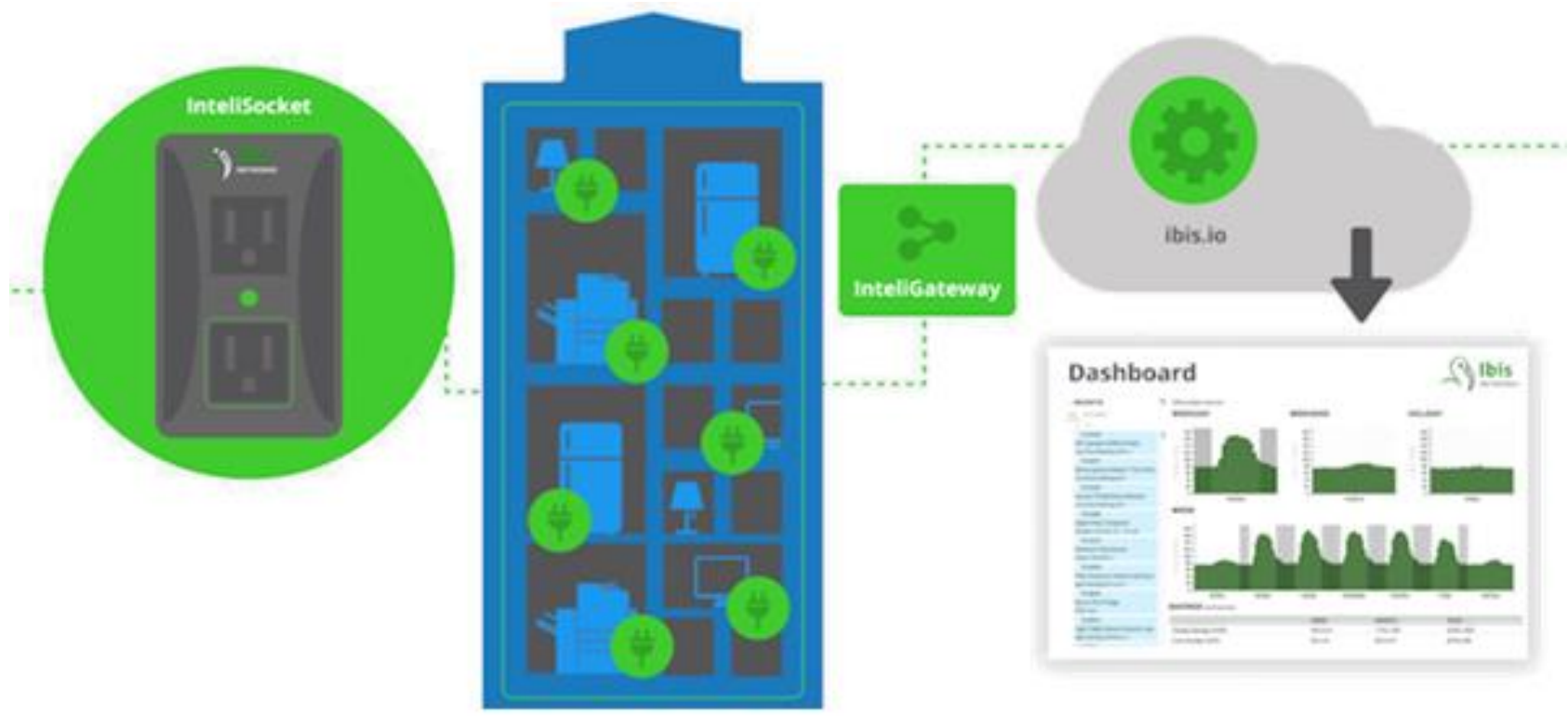

Figure 5. Ibis Data Streams, Gateway, and Platform. ${ }^{7}$

Data streams, repositories, and the platforms that they serve, are the critical elements leveraged to enable model-predictive controls, autonomous controls, and active demand management in buildings. These solutions can achieve value through both economic measures and system control mechanisms such as demand response, transactive energy, microgrid control, and grid-interactive renewables, among others. In all instances, active demand management systems fundamentally require data streams to be relevant for buildings.

Current offerings are most relevant to buildings with many building loads and occupants to manage. The encompassed set of solutions, therefore, is currently relevant for medium and large commercial buildings and campuses. Given the depth of integration these solutions will require with the physical building components and systems, they are more cost-effective in a new-construction environment as opposed to existing buildings. Buildings must have a network of installed gateways that combine data streams from various connected

\footnotetext{
${ }^{7}$ Source: $\underline{\text { http://ibisnetworks.com/ibissystem/ }}$
} 
equipment and data-streaming components to allow communication between the building, the aggregating platform, and the building's systems.

\subsubsection{State of the Art}

Well architected data streams and repositories, as critical components of integration and optimization solutions, are becoming increasingly important for managing the large volumes of data from smart commercial building applications (particularly for lighting, HVAC, and renewables). New products can include a variety of smart, data streaming components, as well as software platforms to act on the component data outputs. These solutions can enable both building-level and grid-level efficiency making them beneficial to both energy providers and consumers. For example, grid-interactive renewables allow consumers to tie in to the grid only when most beneficial for them or the utility, ensuring that customers and utilities are minimizing costs, while also contributing to the reliability of a utility's grid by providing excess energy during peak hours. This is only available to smart buildings if utilities or grid-operators can signal grid status and requirements.

Table 7. Cutting Edge Solutions for Data Streams and Repositories.

\begin{tabular}{|c|c|}
\hline Organization & Solution \\
\hline Honeywell & Smart Grid Solutions \\
\hline $\begin{array}{l}\text { Price-based demand resp } \\
\text { prices and signals betwee } \\
\text { Solution provider website }\end{array}$ & $\begin{array}{l}\text { a singular software platform that sends and receives } \\
\text { control devices and a utility customer } \\
\text { honeywellsmartgrid.com/en-US/Pages/default.aspx }\end{array}$ \\
\hline DesignLights Consortium & Networked Lighting Control (NLC) Systems \\
\hline $\begin{array}{l}\text { Database for the collectio } \\
\text { utilizes scripts to map pro } \\
\text { formats. } \\
\text { Project report available: } \underline{\mathrm{h}} \\
\text { savings-report/ }\end{array}$ & $\begin{array}{l}\text { om Network Lighting Control Systems. The database } \\
\text { base fields and standardize data of } 18 \text { different data } \\
\text { S.org/lighting-controls/reports-tools-resources/nlc-energy- }\end{array}$ \\
\hline Ibis & Plug Load Management System \\
\hline $\begin{array}{l}\text { Plug load management sy } \\
\text { gateways, which, in turn, } \\
\text { data visualization } \\
\text { Solution provider website }\end{array}$ & $\begin{array}{l}\text { stem of intelligent sockets linked together by intelligent } \\
\text { telligent network allowing cloud based configuration and } \\
\text { tworks.com/ibissystem/ }\end{array}$ \\
\hline PNNL & VOLTTRON \\
\hline $\begin{array}{l}\text { Software platform for real } \\
\text { enabling information exch } \\
\text { DOE VOLTTRON website a }\end{array}$ & $\begin{array}{l}\text { ed control; the platform is both open-source and modular, } \\
\text { holders. } \\
\text { gov/eere/buildings/volttron }\end{array}$ \\
\hline FirstFuel & $\begin{array}{l}\text { Key intelligence and software to engage all commercial } \\
\text { energy customers }\end{array}$ \\
\hline $\begin{array}{l}\text { Energy platform for utilitie } \\
\text { opportunities for custome } \\
\text { better understand their n€ } \\
\text { Solution provider website }\end{array}$ & $\begin{array}{l}\text { mer data and better understand energy use and savings } \\
\text { allows utilities to better engage with their customers and } \\
\text { e and refine the services they provide. } \\
\text { irstfuel.com/solutions/overview/ }\end{array}$ \\
\hline
\end{tabular}


Data Lake for intelligent data storage and analytics as a 'smart' alternative to data repositories. Microsoft's

Real Estate and Facilities organization carries out machine learning for predictive maintenance, climate control, and HVAC optimization on the Azure platform. ${ }^{8}$

Solution provider website available: https://azure.microsoft.com/en-us/solutions/data-lake/

\begin{tabular}{l|l} 
OpenFogConsortium & OpenFog Architecture Overview
\end{tabular}

System architecture ${ }^{9}$ enabling fog (or edge) computing as an addendum to or expansion of ubiquitous cloud computing technologies. Fog computing leverages the different levels of a network's topology to conduct stratified analytics for increased reliability, performance, and serviceability.

Technology overview available: https://www.openfogconsortium.org/wp-content/uploads/OpenFog-

Architecture-Overview-WP-2-2016.pdf

\begin{tabular}{l|l} 
IEEE & Real-Time Integration of Building Data
\end{tabular}

Data Stream Management Systems (DSMSs) as a replacement to conventional Database Management Systems (DBMSs) in supporting EMS. Unlike DBMSs that cause latency in data evaluation, DSMSs processes data in real-time allowing real-time system controls.

Technology overview available: https://www.researchgate.net/publication/266202668 Real-

Time Integration of Building Energy Data

NIBS

Database for Analyzing Sustainable and High-Performance Buildings

Database for the streamlining of data collection surrounding sustainable, high performance buildings. The tool incorporates information from existing building databases, companies, organizations, and researchers to increase the quantity, quality, and ease of access for building data.

Project overview available:

https://c.ymcdn.com/sites/www.nibs.org/resource/resmgr/HPBDATA/Read_Summary.pdf?hhSearchTerms $=\% 22$ metric $\% 22$

\begin{tabular}{l|l}
\hline Oracle & Oracle Solutions for Utilities
\end{tabular}

Utility operations management tools including Meter Data Management and Network Management Systems. These solutions offer a good example of uniform, plug-and-play tools for energy-data handling. Their platform, capable of handling large volumes of metering and billing data, can be leveraged for data handing of other building energy data for both utility and non-utility clients.

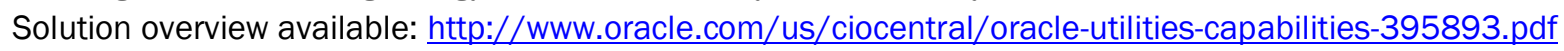

\subsubsection{Recent R\&D}

Key R\&D efforts related to data streams and repositories focus on establishing procedures for control systems and validating, at a high-level, solution performance and building impact. A significant amount of research is required to develop increased uniformity in building IT infrastructure requirements and protocols. The current lack of uniformity in buildings adds expense in retrofit applications that hinders the use of these solutions and limits the applicability of many analytics and optimization solutions to new construction. Future activities related to data streams and repositories should enable consistency and standardization in building data collection as it is used to inform design and operations.

\footnotetext{
${ }^{8}$ More at: https://www.microsoft.com/itshowcase/Article/Content/845/Data-analytics-and-smart-buildings-increase-comfort-and-energyefficiency

${ }^{9}$ More at: https://www.openfogconsortium.org/wp-content/uploads/OpenFog Reference Architecture 2 09 17-FINAL.pdf
} 
Significant research is also ongoing to determine the best methods through which to enable large-scale transactive energy systems. Investigations primarily seek to identify means for improved adoption of transactive energy technologies as opposed to developing the enabling technologies.

Table 8. Recent R\&D for Data Streams and Repositories

\begin{tabular}{|c|c|}
\hline Organization/Investigators & \&D Activity \\
\hline NREL & $\begin{array}{l}\text { Lessons Learned from Case Studies of Six High- } \\
\text { Performance Buildings }\end{array}$ \\
\hline \multicolumn{2}{|c|}{$\begin{array}{l}\text { Providing guidance from case studies of high-performance buildings to determine best practices and impact } \\
\text { on environment and energy use, with commentary on controllers } \\
\text { Lessons learned report available: https://www.nrel.gov/docs/fy06osti/37542.pdf }\end{array}$} \\
\hline Demand Response Research Center at LBNL & $\begin{array}{l}\text { Introduction to Commercial Building Control Strategies } \\
\text { and Techniques for Demand Response }\end{array}$ \\
\hline \multicolumn{2}{|c|}{$\begin{array}{l}\text { Performing analysis to define specific control strategies for commercial buildings that can simultaneously } \\
\text { meet savings targets while minimizing negative impacts on occupants or building systems. One primary } \\
\text { hindrance to achieving the full automation of control strategies involves the inconsistent resolutions of } \\
\text { controls (particularly in HVAC vs lighting controls). } \\
\text { Research report available: http://gaia.lbl.gov/btech/papers/59975.pdf }\end{array}$} \\
\hline USACE & HVAC Control Systems \\
\hline \multicolumn{2}{|c|}{$\begin{array}{l}\text { Describing the impact of Direct Digital Control in BAS for the control of HVAC systems. Listed benefits } \\
\text { include a more competitive procurement process, management of numerous system and sub-system } \\
\text { operations, a user-friendly GUI, and a "whole-building" approach to systems integration. } \\
\text { Article available: https://www.wbdg.org/files/pdfs/usace hvac controlsystems.pdf }\end{array}$} \\
\hline Environmental Defense Fund & A Primer on Time-Variant Electricity Pricing \\
\hline \multicolumn{2}{|c|}{$\begin{array}{l}\text { Evaluating the benefits and approaches to Time-Variant Electricity Pricing for utility customers; solutions can } \\
\text { offer an array of benefits, including but not limited to: decreased energy cost for customers, improved } \\
\text { distributed energy resources, and decreased capacity investments } \\
\text { EDF Report available: https://www.edf.org/sites/default/files/a primer on time-variant pricing.pdf }\end{array}$} \\
\hline IEEE & $\begin{array}{l}\text { Cost-benefit analysis for proactive consumers in a } \\
\text { microgrid for transactive energy management systems }\end{array}$ \\
\hline \multicolumn{2}{|c|}{$\begin{array}{l}\text { Analyzing cost-benefit of consumer participation in microgrid transactive energy management systems, } \\
\text { particularly in the case of a photovoltaic (PV) system coupled with battery energy storage (BES) for improved } \\
\text { customer transactive energy management (TEM) } \\
\text { Conference paper available: } \mathrm{http}: / / \text { ieeexplore.iee.org/document/7749343/ }\end{array}$} \\
\hline Smart Electric Power Alliance & $\begin{array}{l}\text { Transactive energy pilot to test customer acceptance of } \\
\text { real-time pricing scheme }\end{array}$ \\
\hline \multicolumn{2}{|c|}{$\begin{array}{l}\text { Research to evaluate customer acceptance of real-time pricing schemes, with particular attention to how } \\
\text { utilities can overcome customer perceptions that accompany transactive energy measures } \\
\text { Article available: https://sepapower.org/knowledge/transactive-energy-pilot-to-test-customer-acceptance-of- } \\
\text { real-time-pricing-scheme/ }\end{array}$} \\
\hline IEEE & Optimal time-of-use pricing for residential load control \\
\hline \multicolumn{2}{|c|}{$\begin{array}{l}\text { Determining approaches to maximizing demand response potential for time-varying tariffs; for example, } \\
\text { identifying novel algorithms to help utilities optimize their time of use (TOU) pricing based on energy supply } \\
\text { and demand } \\
\text { Report available: } \text { http://ieeexplore.ieee.org/abstract/document/6102350/ }\end{array}$} \\
\hline
\end{tabular}


Determining opportunities for improved integration of electric vehicle supply equipment with the grid solutions include a combination of various end-use services, energy market services, and grid services, which can each contribute to a reduction of cost, energy use, and emissions associated with electric vehicle charging

Guide available: https://www.nrel.gov/docs/fy15osti/64007.pdf

\section{BEDES}

BEDES Dictionary

A dictionary of terms, definitions, and field formats, referred to as the Building Energy Data Exchange Specification (BEDES), utilized to facilitate data transfer of building energy use and characteristics. The common definitions allow for the development of a software ecosystem for building energy characterization founded on common terms.

Project description available: https://energy.gov/eere/buildings/building-energy-data-exchangespecification-bedes

\begin{tabular}{|l|l}
\hline BuildingSync & BuildingSync Schema
\end{tabular}

Language to assist in the standardization of data exchange for commercial building energy audits. Such a language can allow software developers to develop tools that can freely exchange data between sources. Project description available: https://energy.gov/eere/buildings/buildingsync

\section{DesignLights Consortium \\ Energy Savings from Networked Lighting Control (NLC) Systems}

The report details the successes of NLC Systems from an energy perspective, with particular details surrounding the performance of the database and data handling. The report lists numerous findings and recommendations associated with the data handling in this project. The findings include the need to streamline data authorization for improved data collection and remote data access, as well as a need for improved data-export mechanisms for more granular reporting of building data into utility program evaluations. The data-related recommendations include a need for utility NLC programs to require or incentivize anonymized data sharing for participating projects, a standardized reporting format for those data that can be easily exported, and increased sample size, monitoring duration, and building operational characteristics for future data collection.

Report available: https://www.designlights.org/default/assets/File/Lighting\%20Controls/DLCReport_Energy-Savings-from-Networked-Lighting-Control-NLC-Systems.pdf

\begin{tabular}{l|l}
\hline Project Haystack & Haystack
\end{tabular}

An open source service facilitating the standardized integration of data from loT devices. This initiative seeks to develop data models that can unlock the value from the various smart systems in buildings. Project details available: https://project-haystack.org/

\section{University College Dublin \\ A Review of Wireless-Sensor-Network-Enabled Building Energy Management Systems}

Documents the available building EMS solutions with particular attention to the Wireless Sensor Network (WSN) technologies employed in those systems. The report ultimately proposes a system architecture for BEMS.

Research report available:

https://www.researchgate.net/profile/Aqeel Kazmi2/publication/260135187 A Review of Wireless Sen sor_Network_Enabled_Building_Energy_Management_Systems/links/55a4e44008ae00cf99c92f3a.pdf 


\begin{tabular}{|c|c|}
\hline Organization/Investigators & R\&D Activity \\
\hline University College Dublin & \\
\hline \multicolumn{2}{|c|}{$\begin{array}{l}\text { Details a system for the automated annotation of electricity data in nonintrusive load monitoring solutions. } \\
\text { The research discusses the wireless sensor nodes required to capture sensory stimuli needed to enable the } \\
\text { proposed solution. } \\
\text { Research report available: http://researchrepository.ucd.ie/bitstream/handle/10197/2398/secon- } \\
\text { Schoofs.pdf?sequence=1 }\end{array}$} \\
\hline US DOE & Municipal Solid-State Street Lighting Consortium \\
\hline \multicolumn{2}{|c|}{$\begin{array}{l}\text { Provides technical information pertaining to LED street and area lighting demonstrations to be used in } \\
\text { evaluating emerging technologies for those applications. The resource includes the development of a data } \\
\text { repository to catalogue field experiences and process data to substantially decrease the learning curve for } \\
\text { implementing LED lighting. } \\
\text { Project details available: } \text { https://energy.gov/eere/ssl/doe-municipal-solid-state-street-lighting-consortium }\end{array}$} \\
\hline Building and Construction Authority, Singapore & GBIC-Repository \\
\hline \multicolumn{2}{|c|}{$\begin{array}{l}\text { Development of a central data repository for the collection and analysis of building system and subsystem } \\
\text { data, occupancy data, and calibrated instrumentation data corresponding to other active GBIC Demos. The } \\
\text { Green Buildings Innovation Cluster (GBIC) National Building EE Repository enables the data-driven, platform } \\
\text { based, approach to solving a building's most pressing energy related problems. } \\
\text { Project details available: https://www.bca.gov.sg/Researchlnnovation/gbic.html }\end{array}$} \\
\hline NIBS & Data Needs for Achieving High-Performance Buildings \\
\hline \multicolumn{2}{|c|}{$\begin{array}{l}\text { Characterization of the current landscape of high-performance building data with detailed recommendation } \\
\text { for the improvement of building-data infrastructure. Primary recommendations for energy related data } \\
\text { include increasing the purview of such databases such as CBECS as well as increasing the variety and } \\
\text { granularity of energy data at the individual building or building-system level. } \\
\text { Research report available: } \\
\text { https://c.ymcdn.com/sites/www.nibs.org/resource/resmgr/HPBDATA/NIBS_DataCollectionReport.pdf }\end{array}$} \\
\hline
\end{tabular}

\subsection{Advanced Commissioning}

Advanced commissioning solutions seek to address operational deficiencies affecting building energy savings and occupant comfort. These solutions deviate from standard commissioning because they are not singular events in a building's management life-cycle (such as New Construction Commissioning [NCCx] recommissioning [Re-CX], or Retro-Commissioning [RCX]). Instead, these solutions focus on commissioning as an ongoing and holistic process as opposed to a singular event for new or retrofit building applications. Currently used advanced commissioning terminology includes both:

1. Continuous Commissioning (CCx) to track and optimize building technology performance, as well as updating of documentation, staff training, and energy consumption verification and.

2. Monitoring Based Commissioning (MBCx), wherein building-energy data drives a continuous commissioning process like that of CCx.

Advanced commissioning solutions typically benefit any building using commercial-scale equipment, including many multi-family buildings. Figure 6 reviews the various types of commissioning. 


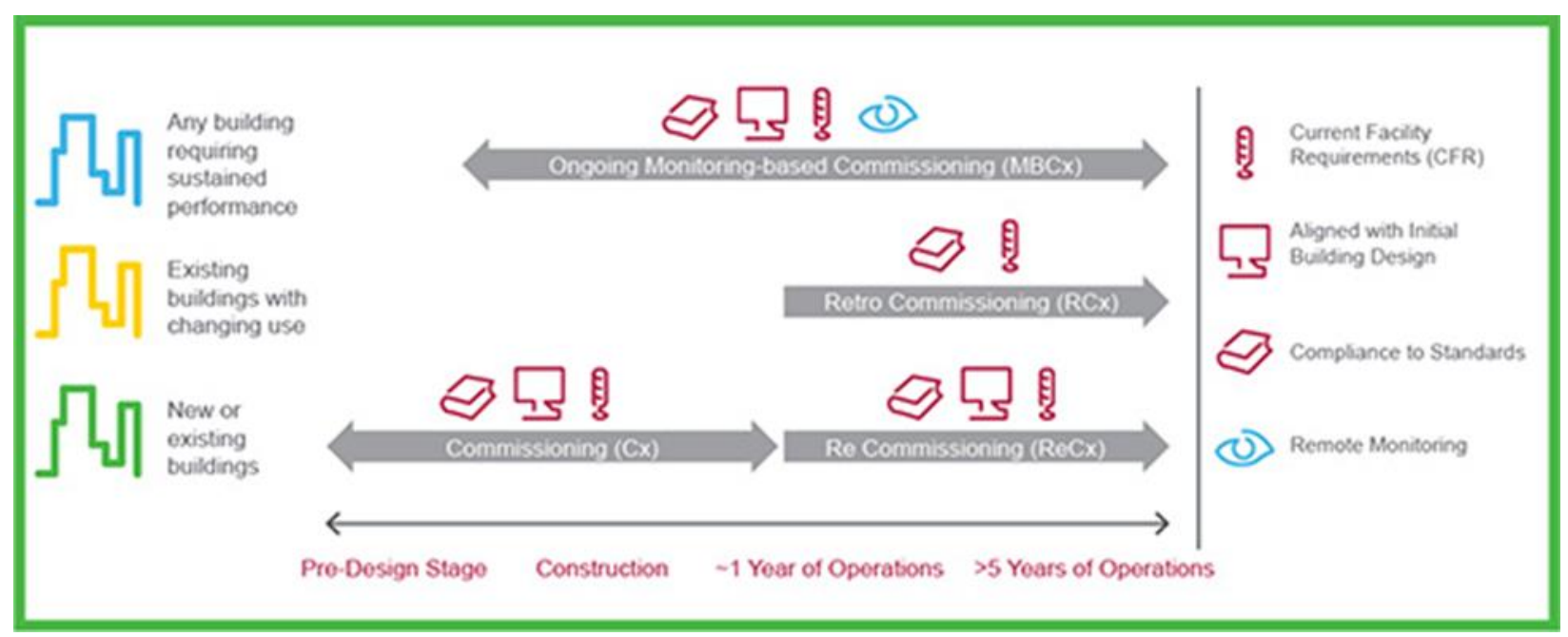

Figure 6. Commissioning types, uses, and applications. ${ }^{10}$

\subsubsection{State of the Art}

Existing solutions are gaining traction but are not exhaustive and require customization. While many solutions exist at an equipment or component level, emerging solutions seek to cover buildings through a holistic assessment of the building's subsystems. Table 9 highlights some of the leading solutions, solution providers, and processes.

Table 9. Cutting Edge Solutions for Advanced Commissioning.

\begin{tabular}{|c|c|}
\hline Organization & Solution \\
\hline NIST & HVAC-Cx Building HVAC Systems Commissioning Tool \\
\hline \multicolumn{2}{|c|}{$\begin{array}{l}\text { Automated software for HVAC system commissioning; solution can execute functional performance testing } \\
\text { as well as continuous monitoring of deployed HVAC equipment }\end{array}$} \\
\hline EnerNOC & New Building Commissioning Services \\
\hline \multicolumn{2}{|c|}{$\begin{array}{l}\text { Mining data from building systems to achieve energy savings and cost reductions (estimated at 8-20\% } \\
\text { equipment life); solution spans the design, construction, acceptance, and post-occupancy phases of a } \\
\text { building's life } \\
\text { Solution provider website available: https://www.enernoc.com/resources/datasheets-brochures/get- } \\
\text { started-right-enernocs-new-building-commissioning-services }\end{array}$} \\
\hline UC/CSU/IOU & 24 Monitoring-Based Commissioning Projects \\
\hline \multicolumn{2}{|c|}{$\begin{array}{l}\text { Permanent framework for system verification and management; identified } 1120 \text { building issues pertaining } \\
\text { to HVAC equipment ( } 65 \% \text { of sites), air-handling and distributions systems ( } 59 \% \text { of sites), cooling plants ( } 29 \% \\
\text { of sites), heating plants ( } 24 \% \text { of sites), and terminal units ( } 24 \% \text { of sites) } \\
\text { Project benchmarking report available: https://eetd.Ibl.gov/sites/all/files/publications/lbnl-1972e.pdf }\end{array}$} \\
\hline
\end{tabular}

${ }^{10}$ Source: https://www.linkedin.com/pulse/building-commissioning-so-great-why-doesnt-every-do-melanie/ 
Uniform software solution that can be customized for individual buildings for real-time insight into building energy use. This energy management platform leverages meter, sub-meter, BMS data, and loT devices for real-time analysis enabling advanced commissioning.

Solution provider website available: https://lucidconnects.com/solutions

\begin{tabular}{l|l} 
Siemens & Monitoring-Based Commissioning (MBCx)
\end{tabular}

Software package to manage incoming data streams from various building systems to identify system faults, develop and prioritize systems-improvement recommendations, and convert recommendations to executable work orders

Solution provide white paper available: https://www.downloads.siemens.com/downloadcenter/Download.aspx?pos=download\&fct=getasset\&id1=A6V10702463

\begin{tabular}{l|l} 
NORESCO & Monitoring Based Commissioning
\end{tabular}

MBCx technology package and standardized integration processes for easier acceptance of technology in existing buildings

Solution provide website available: http://www.noresco.com/energy-services/en/us/solutions/EnergyEfficiency-Sustainability-Consulting/Monitoring-Based-Commissioning/

\subsubsection{Recent R\&D}

Much of the current research seeks to validate functionality, determine feasibility and usability for various building commissioning applications. Limited early-stage research and development is ongoing to attain technology improvements. The most impactful advanced commissioning solutions, however, will need to overcome a substantial cultural trend and both document the value of commissioning and enable easy, consistent usage by owners and operators. Consequently, some of the on-going R\&D also seeks to simplify the use of advanced commissioning processes within existing building management practices.

Table 10. Recent R\&D for Advanced Commissioning.

\begin{tabular}{|c|c|}
\hline Organization/Investigators & R\&D Activity \\
\hline $\begin{array}{l}\text { ACEEE; California Institute } \\
\text { for Energy and Environment }\end{array}$ & $\begin{array}{l}\text { Monitoring-Based Commissioning: Tracking the Evolution and Adoption of a } \\
\text { Paradigm-Shifting Approach to Retro-Commissioning }\end{array}$ \\
\hline \multicolumn{2}{|c|}{$\begin{array}{l}\text { Analyzing case studies of continuous commissioning efforts to identify the quality of data collected, } \\
\text { persistence of energy savings, and residual barriers minimizing the efficacy of continuous commissioning } \\
\text { solutions } \\
\text { ACEEE paper available: http://aceee.org/files/proceedings/2012/data/papers/0193-000137.pdf }\end{array}$} \\
\hline $\begin{array}{l}\text { Building Commissioning } \\
\text { Association; Newcomb | } \\
\text { Anderson | McCormick }\end{array}$ & $\begin{array}{l}\text { Quantifying Monitoring-Based Commissioning in Campus } \\
\text { Buildings: Utility Partnership Program Results, Lessons } \\
\text { Learned, and Future Potential }\end{array}$ \\
\hline \multicolumn{2}{|c|}{$\begin{array}{l}\text { Quantifying benefits from monitoring-based commissioning for campus buildings and utility partnership } \\
\text { the findings provide initial quantification of the savings achieved at each of the } 25 \text { campuses with MBC } \\
\text { solutions } \\
\text { Conference paper available: http://www.bcxa.org/ncbc/2007/proceedings/Anderson_NCBC2007.pdf }\end{array}$} \\
\hline NIST & $\begin{array}{l}\text { Automated Fault Detection and Diagnostics for the Mechanical Services in } \\
\text { Commercial Buildings Project }\end{array}$ \\
\hline \multicolumn{2}{|c|}{$\begin{array}{l}\text { Developing novel software algorithms that can enable automated fault detection diagnostics in commercial } \\
\text { buildings utilizing data typically found in standard control hardware already deployed with systems' } \\
\text { equipment }\end{array}$} \\
\hline
\end{tabular}




\section{Organization/Investigators R\&D Activity}

NIST project details available: https://www.nist.gov/programs-projects/automated-fault-detection-anddiagnostics-mechanical-services-commercial-buildings

\begin{tabular}{l|l}
\hline LBNL & Using EMIS to Identify Top Opportunities
\end{tabular}

for Commercial Building Efficiency

Evaluating the efficacy by which energy management and information system (EMIS) technologies can diagnose building energy losses and identify opportunities for building energy savings; EMIS solutions can enable continuous advanced commissioning and have an estimated savings of between $10 \%$ and $20 \%$ of site energy.

Research report available: https://eta.Ibl.gov/sites/all/files/publications/1007250.pdf

\section{Opportunities and Conclusion}

Several themes emerged for each of the research categories in Section 3. This section documents notable trends, research gaps, and opportunities for growth in each of the research categories:

\section{Integrated Multi-Technology Efficiency Packages}

- Trends - There are several emerging technologies and solutions under development within this category, but few are commercialized; they have been hindered by manufacturers, distributors, and trades that have historically been siloed and are not sufficiently integrated to easily deploy optimized, multi-technology solutions.

- $\quad$ Literature Themes - The R\&D literature available primarily focuses on the quantification of savings possible with systems-based approaches relative to traditional widget-based approaches, both in a lab setting and in the field. Successful results within these investigations can motivate the development of more integrated multi-technology efficiency packages.

- R\&D Gaps - Additional evaluation is needed to prioritize specific high impact packages and the associated $R \& D$ integration opportunities. Inconsistent $M \& V$ approaches hinder this by limiting comparability of results.

\section{Integrated and Optimized Design for New Construction}

- Trends - Existing tools and processes are primarily focused on improved interactions and communications among design-team members. Consequently, such solutions are often implemented independently by individual firms based on available design guides. Current solutions are still at time hindered by suboptimal contracts, and an inability to readily incorporate existing building data into the early phases of building design and modeling, particularly real building data that is useful for whole building optimization.

- Literature Themes - Integrated design process research seeks improvements in data- and softwareenabled solutions. Data-driven modeling tools can simulate the performance of various building systems, simultaneously, to analyze the impact of various design changes. Substantial amounts of research are dedicated to advancing these tools, but also to determining the role they should play in integrated design process workflows for design teams. Research into the quantification of savings possible from early collaboration is also gaining traction as a way to justify and create a business case for implementing these (often costly) approaches. 
- R\&D Gaps - Additional research is needed to pull out best practices and model methods for datadriven design approaches and how these approaches translate to post-construction operations. Additionally, these data-driven integrated design approaches need to accommodate newer and larger sets of real building data. A primary concern for developers of these modeling tools is how to handle the plethora of data generated by more sophisticated building energy models and the real-world data that can be leveraged from a range of sources. $R \& D$ that streamlines data into software design tools/considerations, reduces data processing times and increases the volume of data that can be easily analyzed can impact both the efficacy and usefulness of these technologies.

\section{Energy Management Information Systems (EMIS)}

- Trends - EMIS from several commercially available solution providers are quickly gaining adoption in many buildings. The most promising solutions are extensible, cloud-based platforms with intuitive, visual user interfaces. The solutions share many similarities, but all differ in implementation, target building type(s), and ideal use cases, making comparisons between solutions challenging.

- Literature Themes - Much of the current $R \& D$ is focused on improving the performance of the underlying hardware for EMIS (sensors, wireless networks, etc.) and optimizing the physical deployment of that hardware to reduce the cost of the infrastructure. Software and algorithm R\&D is continually evolving in all respects as vendors learn and improve their systems.

- $\quad$ R\&D Gaps - EMIS could benefit from further research into solutions that increase data handling process sophistication to match growing building EMIS needs. This may include aggregation and management of existing building datasets as a basis for machine-learning, system/whole-building optimization and possible autonomous building operation. Many existing EMIS solutions do not have the capacity to interface with such a large and varied set of data sources. The necessary R\&D advancements for EMIS are closely tied to, and build from, those related to data streams and repositories (see below).

\section{Data Streams and Repositories}

- Trends - Data streams from building systems are continually growing in number and volume as advanced, connected smart building sensing technologies become ubiquitous in new construction and retrofit projects. This leads to a greater need for more consistency in IT infrastructure, better, faster processing algorithms, and smarter ways to collect, share and structure data repositories. Decisions on how to manage the flow of data, maintain data quality, recover from communication disruptions, and quickly process such large volumes of data are increasingly vital to successful deployment of the EMIS and other systems that use the data.

- Literature Themes - The leading building data collection method involves the aggregation and storage of static data elements, often in a building-specific repository. The data streams may be collected and stored with numerous incompatible formats and communication protocols, requiring extra hardware and software processing layers. Such methods can accommodate current data volumes but may need scalability improvement in the future. Example research covers concepts like "data lakes" and "fog", or "edge computing", as more efficient data handling solutions than today's typical repositories. These solutions generally seek to distribute analysis and processing loads to a range of nodes in the system (e.g. individual building systems) for simultaneous analyses and real-time controls as opposed to having one central repository from which data is analyzed.

- R\&D Gaps - Existing and emerging solutions are inconsistent in the formats of their data, architecture, and interoperability, making it difficult to integrate and share across buildings, communities and for national use. As connected buildings and building systems become more prevalent, there is a need to standardize building data elements to reduce data processing loads and enable consistency in repositories. 


\section{Advanced Commissioning}

- Trends - The overall trend for commissioning is to move away from single commissioning events and towards ongoing commissioning processes. Current advanced commissioning systems require substantial customization in the installation process to integrate all the various systems from different manufacturers in a building. Future systems seek to leverage existing sensing and analytics capabilities via plug-and-play compatibility.

- Literature Themes - Recent research has sought to quantify savings of advanced commissioning systems. The R\&D for innovative improvements has focused on the development and evaluation of methods for integrating with sensors and other hardware in existing building systems instead of requiring the installation of additional sensors specifically for the commissioning system (duplicating those within equipment in many cases). Key R\&D on this topic covers communication protocols and processing algorithms. To date, research has focused on a small selection of equipment types.

- R\&D Gaps - For advanced commissioning solutions to work with sensors that exist already in building equipment (and on all equipment in the building), additional research is needed to:

0 understand the most important building (sensing and control) data points are necessary to create the highest impact energy savings,

- ensure that most buildings have connectivity across those data points and,

- enable the standardization of those data outputs to enable plug-and-play type integration with advanced commissioning systems.

This research will require close collaboration between manufacturers and standards organizations to help determine the best path to creating building systems that are advanced-commissioning-ready out of the box. 


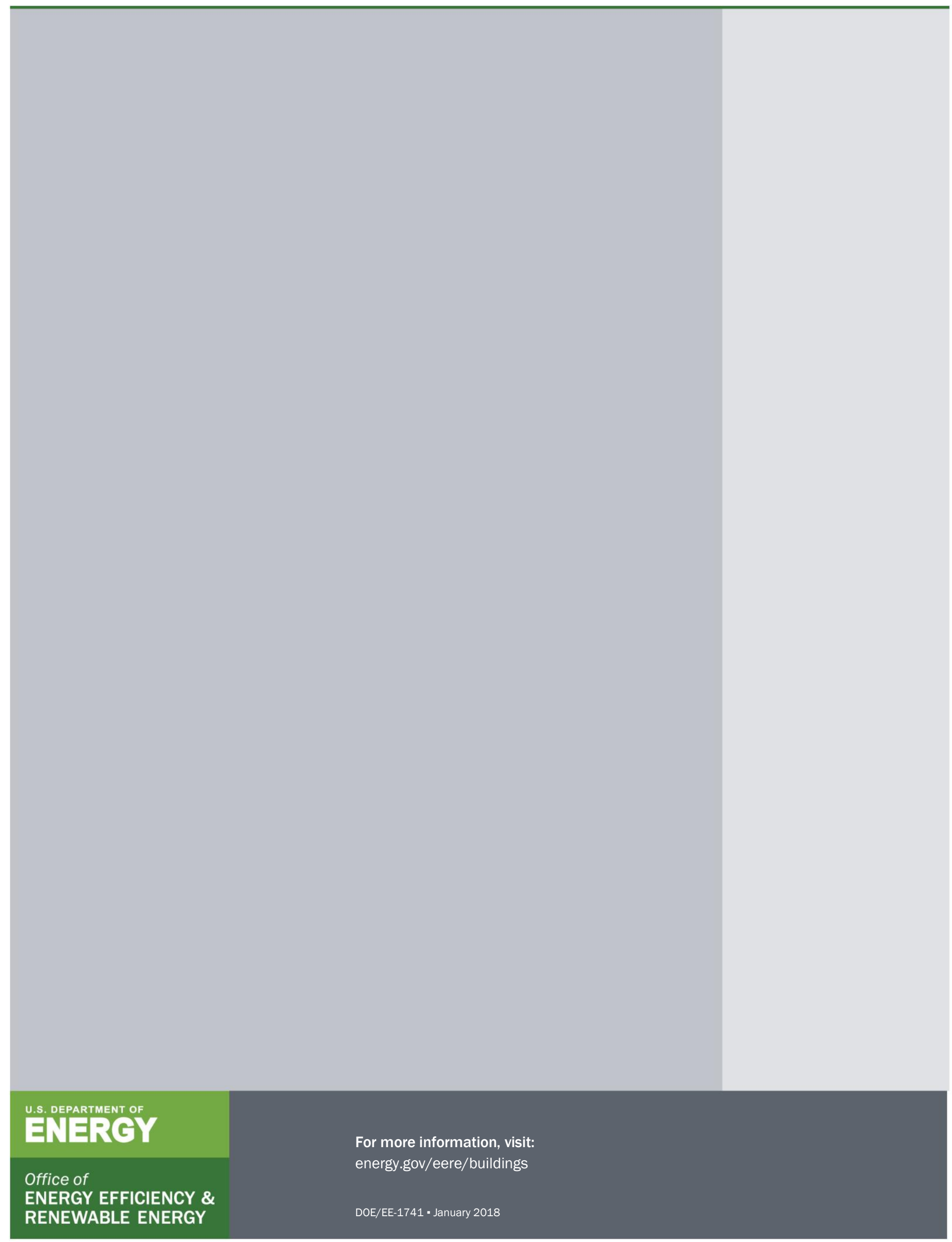

